\title{
Resistance to DDT and Pyrethroids and Increased kdr Mutation Frequency in An. gambiae after the Implementation of Permethrin-Treated Nets in Senegal
}

\author{
Mamadou O. Ndiath ${ }^{1}$, Seynabou Sougoufara ${ }^{1}$, Abdoulaye Gaye $^{1}$, Catherine Mazenot ${ }^{1}$, Lassana Konate ${ }^{2}$, \\ Oumar Faye ${ }^{2}$, Cheikh Sokhna ${ }^{1 *}$, Jean-Francois Trape ${ }^{1}$
}

1 Institut de Recherche pour le Développement, Unité de Recherche sur les Maladies Infectieuses et Tropicales Emergentes (URMITE) UMR 198, Campus commun UCADIRD de Hann, BP 1386, CP 18524, Dakar, Sénégal, 2 Laboratoire Ecologie Vectorielle et Parasitaire, UCAD, Fann Dakar, Sénégal

\begin{abstract}
Introduction: The aim of this study was to evaluate the susceptibility to insecticides of An. gambiae mosquitoes sampled in Dielmo (Senegal), in 2010, 2 years after the implementation of Long Lasting Insecticide-treated Nets (LLINs) and to report the evolution of kdr mutation frequency from 2006 to 2010.

Methods: WHO bioassay susceptibility tests to 6 insecticides were performed on adults F0, issuing from immature stages of An. gambiae s.l., sampled in August 2010. Species and molecular forms as well as the presence of L1014F and L1014S kdr mutations were assessed by PCR. Longitudinal study of kdr mutations was performed on adult mosquitoes sampled monthly by night landing catches from 2006 to 2010.

Findings: No specimen studied presented the L1014S mutation. During the longitudinal study, L1014F allelic frequency rose from $2.4 \%$ in year before the implementation of LLINs to $4.6 \%$ 0-12 months after and 18.7\% 13-30 months after. In 2010, An. gambiae were resistant to DDT, Lambda-cyhalothrin, Deltamethrin and Permethrin (mortality rates ranging from 46 to $63 \%)$ but highly susceptible to Fenitrothion and Bendiocarb (100\% mortality). There was significantly more RR genotype among An. gambiae surviving exposure to DDT or Pyrethroids. An. arabiensis represented $3.7 \%$ of the sampled mosquitoes $(11 / 300)$ with no kdr resistance allele detected. An. gambiae molecular form M represented $29.7 \%$ of the mosquitoes with among them, kdr genotypes SR (18\%) and SS (82\%). An. gambiae molecular form S represented $66 \%$ of the population with, among them, kdr genotype SS (33.3\%), SR (55.6\%) and RR (11.1\%). Only 2 MS hybrid mosquitoes were sampled and presented SS kdr genotype.
\end{abstract}

Conclusion: Biological evidence of resistance to DDT and pyrethroids was detected among An. gambiae mosquitoes in Dielmo (Senegal) within 24 months of community use of LLINs. Molecular identification of L1014F mutation indicated that target site resistance increased after the implementation of LLINs.

Citation: Ndiath MO, Sougoufara S, Gaye A, Mazenot C, Konate L, et al. (2012) Resistance to DDT and Pyrethroids and Increased kdr Mutation Frequency in An. gambiae after the Implementation of Permethrin-Treated Nets in Senegal. PLoS ONE 7(2): e31943. doi:10.1371/journal.pone.0031943

Editor: Rick Edward Paul, Institut Pasteur, France

Received September 1, 2011; Accepted January 20, 2012; Published February 22, 2012

Copyright: (C) 2012 Ndiath et al. This is an open-access article distributed under the terms of the Creative Commons Attribution License, which permits unrestricted use, distribution, and reproduction in any medium, provided the original author and source are credited.

Funding: This work was supported by the French Ministry of Research and the Department Support and Formation of the south communities of the Research Institute for the Development (IRD). The funders had no role in study design, data collocation and analysis, decision to publish, or preparation of the manuscript.

Competing Interests: The authors have declared that no competing interests exist.

* E-mail: cheikh.sokhna@ird.fr

\section{Introduction}

Recently, huge progress has been made in the control of malaria in Sub Saharan African countries [1,2]. In Senegal, between 2006 and 2009, malaria proportional morbidity fell from $33.57 \%$ to $3.1 \%$. During the same period, proportional mortality decreased from $18.17 \%$ to $4.4 \%$ [3]. These changes followed the introduction of new prevention, diagnostic and treatment polices [4]. As recommended by WHO, control strategy included actions to targeting malaria parasite vectors including indoor residual spraying (IRS), the use of long-lasting insecticide-treated bed nets (LLINs) and the destruction of larvae breeding sites [5]. The major challenge faced by vector control programs is the development of resistance to insecticides [6]. In recent years, the widespread use of insecticides in agriculture [7] but also for bed net treatment [8,9] contributed to the selection of resistant mosquito strains. Resistance to pyrethroids is a particular threat for malaria control, since they are currently the only recommended and approved insecticides for treating bed nets, primarily because of their low toxicity for humans compared to other pesticides [10].

Mosquitoes' resistance to insecticide has been demonstrated by both in vivo biological test and by the identification of resistance alleles in a vast number of sites across Africa. Especially, kdr mutation genotype has been recognized to be related to DDT and pyrethroid resistance [11]. An. gambiae s.l. and An. funestus are the two major malaria vectors in Dielmo (Senegal) [12]; both have previously been found to be potentially resistant to pyrethroids $[13,14]$. The resistance to insecticide has been shown to be locally 
highly variable even inside a country or a region [15-19]. An early detection of resistance is necessary for the implementation of rational vector control programs [20]. It will not be possible to have reliable information without a regular and tight mapping of the resistance status of mosquitoes.

Since 1990, an epidemiological study is ongoing in Dielmo (Senegal) that involves long-term investigations on host-parasite relationships and mechanisms of protective immunity in residents of this Senegalese village [21]. For the first time in Senegal, universal coverage with LLINs (Permanet ${ }^{\circledR} 2.0$ ) was implemented in Dielmo in July 2008. After a dramatic decrease in malaria morbidity observed after the implementation of LLINs, a rebound was observed in this village 2 years later [22]. In order to identify the causes for increased morbidity, a study of mosquito susceptibility to insecticide was needed. This paper reports the evolution of the presence of kdr mutation, in Anopheles gambiae s.l., 2 years before and after the implementation of LLINs and the results of resistance tests to 6 frequently used insecticides performed in 2010, 2 years after the implementation of LLINs.

\section{Methods}

\section{Mosquito sampling}

This study is part of the Dielmo Project that has been described in detail elsewhere [21]. Briefly, the village of Dielmo $\left(13^{\circ} 43 \mathrm{~N}\right.$, $\left.16^{\circ} 24 \mathrm{~W}\right)$ is located $280 \mathrm{~km}$ Southeast of Dakar and about $15 \mathrm{~km}$ north of the Gambian border in an area of Sudan-type savannah. About 400 inhabitants are living in the village. Rainfall occurs during a four-month period, from June to October. Dielmo is situated on the marshy bank of a small permanent stream, with anopheles larval sites present all year round.

Adult mosquitoes were collected by human landing catches (HLC) monthly from July 2006 to December 2010. Night captures (7:00 PM-7:00 AM) were conducted once or more times each month in two indoor and two outdoor sites. In each site, two trained collectors (adult male volunteers) worked alternatively for one hour and rested for one hour. Anopheline identification was performed following the Gillies and DeMeillon morphologic identification keys [23]. Mosquitoes belonging to the Anopheles gambiae sensus lato (s.l.) group were stored for following steps.

In August 2010, during the rainy season, immature stages of $A n$. gambiae s.l. were collected from 10 breeding sites situated in and around the village (river, rain pools and cattle watering places). Larvae were pooled and fed with Tetramin ${ }^{\circledR}$ baby fish food locally until emergence. Unfed 2-3 days female An. gambiae s.l. mosquitoes were used for insecticide susceptibility tests.

\section{Susceptibility test}

Bioassays were carried out using WHO test kits for adults mosquitoes [24] with six insecticides of technical grade quality: one belonging to the Carbamate group ( $0.1 \%$ Bendiocarb), one Organophosphate (1\% Fenitrothion), 3 pyrethroids $(0,05 \%$ Lambda-cyhalothrin, $0.05 \%$ Deltamethrin, 0,75\% Permethrin) and one Organochlorine (4\% DDT). Impregnated papers were obtained from the WHO reference center (Vector Control Research Unit, University Sains Malaysia, Penang, Malaysia). Tests were performed with batches of 25 An. gambiae s.l., with four batches tested against each insecticide. Mosquitoes were exposed to insecticide-impregnated filter paper for 1 hour at $25-27^{\circ} \mathrm{C}$ and $80 \%$ relative humidity. The number of knockdown mosquitoes was recorded at 10, 15, 20, 30, 40, 50, 60 and 80 min. After exposure, mosquitoes were kept in observation tubes and supplied with a $10 \%$ sugar solution. Mortality was recorded after 24 hours. The mortality of a control stain of An. gambiae (Yaoundé known to be $100 \%$ susceptible to all tested insecticides $[25,26]$ ) was studied as a positive control. Batches exposed to untreated papers were used as negative control. Since mortality in negative controls was always $<5 \%$, no adjustment was performed for treated batches. For each insecticide, a sample of 50 An. gambiae s.l. specimens was randomly selected, including equal numbers of dead and surviving specimens (when available) and used for molecular tests.

\section{Molecular identification and kdr genotyping}

In the subsample of mosquitoes used for bioassay and in adults sampled by HLC during the longitudinal study, detection of $\mathrm{L} 1014 \mathrm{~F}$ and L1014S kdr mutations (thereafter identified as kdr-w and kdr-e respectively) was performed by PCR [27,28]. Mosquitoes used for bioassay were identified down to their species and molecular form with the PCR RFLP method [29].

\section{Data analysis}

WHO (1998) criteria were used to evaluate the resistance/ susceptibility status of the tested mosquito populations $(<80 \%$ mortality: resistance, 80-98\% mortality: increased tolerance, $>98 \%$ mortality: susceptibility) [24]. Fifty and 95 percent knockdown times (respectively $\mathrm{KDT}_{50}$ and $\mathrm{KDT}_{95}$ ) were computed with probit regression models. Rates were compared using Fisher exact and Pearson $\mathrm{Chi}^{2}$ tests. Statistical analyses were performed using Stata 10.1 software. A $\mathrm{P}$ value of 0.05 or less was considered as significant.

\section{Ethics approval}

The Dielmo project was initially approved by the Ministry of Health of Senegal and the assembled village population. Approval was then renewed on a yearly basis. Audits were regularly conducted by the National Ethics Committee of Senegal and adhoc committees of the Ministry of Health, the Pasteur Institute and the Institut de Recherche pour le Développement.

\section{Results}

Kdr genotype dynamic in adult An. gambiae s.l.

From July 2006 to December 2010, no specimen with L1014S (kdr-e) mutation was identified.

The repartition of kdr genotype during the study period is presented in Figure 1. Before the implementation of LLINs, L1014F allelic frequency was low and not different when

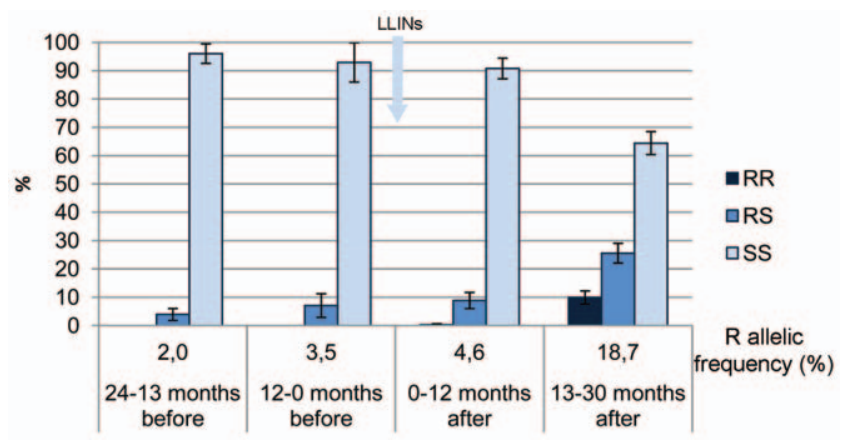

Figure 1. kdr mutation in An. gambiae before and after the implementation of LLINs. Proportion (and $95 \% \mathrm{Cl}$ ) of An. gambiae with L1014F homozygote mutation (RR), heterozygote mutation (RS) or wild type (SS) sampled 24-13 months $(n=228)$ and 12-0 months $(n=99)$ before the implementation of long lasting insecticide-treated nets (LLINs) in July 2008, 0-12 months $(\mathrm{n}=327)$ and $13-30$ months after $(\mathrm{n}=582)$.

doi:10.1371/journal.pone.0031943.g001 
comparing 24-13 months and 12-0 months before periods (2.0 and $3.5 \%$ respectively, $\left.\mathrm{Chi}^{2}=1.4, \mathrm{p}=0.24\right)$. This rate significantly increased to $4.6 \%$ within the first 12 months that followed the distribution of LLINs $\left(\mathrm{Chi}^{2}=4.4, \mathrm{p}<0.05\right.$ vs. pre-implementation) and again $13-30$ months after to $18.7 \%\left(\mathrm{Chi}^{2}=70, \mathrm{p}<0.001\right.$ vs. preceding period) (Figure 1).

\section{Sensitivity to insecticides in 2010}

Mortality data indicated that mosquitoes were highly resistant to 4 of the 6 insecticides tested including DDT and all Pyrethroids (Deltamethrin, Lambda-cyhalothrin and Permethrin). Mortality rates ranged from 46 to $63 \%$, far below the susceptibility limit of $80 \%$ (Table 1). Mosquitoes were totally susceptible to Fenitrothion (Organophosphate) and Bendiocarb (Carbamate) with a $100 \%$ mortality observed for both insecticides.

Knockdown time $50\left(\mathrm{KDT}_{50}\right)$ was higher than 40 minutes for Lambda-cyhalothrin, Permethrin, DDT and Fentrothion and $\mathrm{KDT}_{95}$ exceeded the 80-min observation period (Table 1). Knockdown time was shorter for Deltamethrin $\left(\mathrm{KDT}_{50}=28.0 \mathrm{~min}\right)$ and even shorter for Bendiocarb $\left(\mathrm{KDT}_{50}=17.5\right.$ and $\mathrm{KDT}_{95}$ $=39.0 \mathrm{~min}$ ).

In the 300-specimens sample selected for molecular analysis among dead and surviving mosquitoes, 11 (3.7\%) were $A n$. arabiensis, 89 (29.7\%) An. gambiae s.s. molecular form M, 2 (0.7\%) MS hybrids and $198(66.0 \%)$ form S. When comparing the species and molecular forms of An. gambiae s.l. among dead and surviving mosquitoes, no association could be identified for Deltamethrin, Lambda-cyhalothrin, Permethrin and DDT (Fisher exact test $\mathrm{p}>0.2$, Table 2). This analysis could not be performed for Fenitrothion and Bendiocarb since all mosquitoes died.

\section{Kdr mutations and resistance phenotype}

Among the 300 surviving and dead specimens selected for kdr-w identification, $152(50.7 \%)$ were SS, $126(42 \%)$ SR and $22(7.3 \%)$ RR kdr-w genotype (Table 3). No specimen presented the kdr-e mutation. There was a significant difference in kdr-w genotype between dead and surviving mosquitoes for DDT and all Pyrethroids (Fisher exact p ranging from 0.041 to 0.002). R allelic frequency was significantly higher in survivors for each insecticide (Fisher exact $\mathrm{p} \leq 0.001)$. No RR genotype was identified among dead mosquitoes after DDT or pyrethroids exposure (Table 3). Among survivors, $70 \%$ of specimens presented a mutated allele; $30 \%$ had a resistant phenotype although they did not present $\mathrm{kdr}$ mutation.

The frequency of kdr-w mutation was significantly different according to the molecular form of An. gambiae (Fisher exact test $\mathrm{p}<0.001$, Table 4). Molecular form $\mathrm{S}$ had a specific kdr-w genotype compared to An. arabiensis and An. gambiae s.s. M form
(Fisher exact test $\mathrm{p}<0.001$ in both cases). Allelic form $\mathrm{R}$ was totally absent in An. arabiensis and in An. gambiae MS form. In An. gambiae M form, SR genotype was present (18\%) and RR genotype was absent. Allele R frequency was $38.9 \%$ for molecular form $\mathrm{S}$ vs. $7.8 \%$ in the other groups (Fisher exact test $\mathrm{p}<0.001$ ).

\section{Discussion}

The results of this study demonstrated that field population of An. gambiae s.l. display a high biological level of resistance to DDT and pyrethroids (Deltamethrin, Lambda-cyhalothrin and Permethrin). Similar resistance has been observed all around Africa but little information was previously published about Senegal. Investigations on the biological susceptibility to DDT performed in sentinel sites of Senegal reported a resistance to DDT in 4/10 sites [26] in 2008 and in $11 / 15$ sites in 2010 [25]. In Africa, the resistance to DDT is widespread $[15-18,30]$ with mortality rate as low as $0 \%$ in RDC [31]. On the other hand, total susceptibility to DDT was observed in other countries [19,32] or even in other regions of the same countries [30]. In regions where mosquitoes are still relatively susceptible to DDT, $\mathrm{KDT}_{50}$ is short (6-26 min) [19], whereas in regions where specimens are highly resistant to $\mathrm{DDT}, \mathrm{KDT}_{50}$ is longer (more than the 80 -min observation period) [18]. In our study, although resistance was detected, according to the WHO criteria, mortality rates as well as $\mathrm{KDT}_{50}$ were at an intermediate level.

While the resistance to pyrethroids was limited in 2008 in Senegal (detected in 0/10 sentinel sites for Deltamethrin, 2/11 for Lambda-cyhalothrin and 4/10 for Permethrin [26]), it was found to be widespread in 2010 (detected in $9 / 15$ sites for Deltamethrin, 10/15 for Lambda-cyhalothrin and 12/15 for Permethrin [25]). Resistance to pyrethroids has been reported in various African countries [16-18,30,33]. Whilst full susceptibility to pyrethroids is still reported in other countries [19] or even in other areas of the same countries [18,30,34]. $\mathrm{KDT}_{50}$ was $49 \mathrm{~min}$ in our study, slightly longer than that observed in Dakar in 1995 when susceptibility was higher $(77 \%$ mortality vs. $46 \%$ in our study) [14]. In studies where various pyrethroids were tested, crossresistance or increased tolerance to all pyrethroids was confirmed $[16,17]$. In our study, a cross-resistance to all pyrethroids tested was observed with low mortality rates.

In this study, the presence of kdr-w mutation was detected in $A n$. gambiae s.s.; kdr-e mutation was not identified in any tested taxa. The presence of kdr mutations have been studied all around Africa [33]. While, kdr-w mutation that was initially described in Cote d'Ivoire, has been detected as far East as Uganda, kdr-e that originated in Kenya have spread into Central Africa (for review see [33]) and have recently been found in Benin [35]. Until now,

Table 1. Bioassay susceptibility tests in 2010.

\begin{tabular}{lllllll}
\hline & & & & & \\
\hline & Mortality \% & $\mathbf{9 5 \%} \mathbf{~ C l}$ & KDT $_{\mathbf{5 0}}$ & $\mathbf{9 5 \%} \mathbf{~ C l}$ & $\mathbf{K D T}_{\mathbf{9 5}}$ & $\mathbf{9 5 \%} \mathbf{~ C l}$ \\
\hline Deltamethrin 0,05\% & 63 & {$[53.5-72.5]$} & 28.0 & {$[25.3-30.7]$} & na & - \\
Lambda-cyhalothrin & 60 & {$[50.3-69.7]$} & 43.6 & {$[40.9-46.3]$} & na & - \\
Permethrin 0,75\% & 46 & {$[36.2-55.8]$} & 48.7 & {$[45.5-51.9]$} & na & - \\
DDT 4\% & 61 & {$[51.4-70.6]$} & 64.6 & {$[58.1-71.0]$} & na & - \\
Fenitrothion & 100 & - & 70.4 & {$[67.1-73.7]$} & na & - \\
Bendiocarb 0,1\% & 100 & - & 17.5 & {$[16.4-18.5]$} & 39.0 & {$[37.9-40.0]$} \\
\hline
\end{tabular}

Mortality rate (\%) 24 hours after exposition, 50 and 95\% knockdown (KDT ${ }_{50} \mathrm{KDT}_{95}$ ) time (min) with 95\% confidence interval (Cl), obtained on 100 An. gambiae for each insecticide tested. na: not applicable, $95 \%$ knock down time exceeded $80 \mathrm{~min}$.

doi:10.1371/journal.pone.0031943.t001 
Table 2. Molecular forms of An. gambiae s.l. among dead and surviving mosquitoes after insecticide exposure.

\begin{tabular}{|c|c|c|c|c|c|c|}
\hline & & \multicolumn{4}{|c|}{ Molecular form of An. gambiae s.l. } & \multirow[t]{2}{*}{ Fisher exact test $p$} \\
\hline & & An. arabiensis & $\mathbf{M}$ & MS & $\mathbf{s}$ & \\
\hline \multirow[t]{2}{*}{ Deltamethrin $0,05 \%$} & Dead $n=25$ & $4 \%(1)$ & $36 \%(9)$ & $0 \%(0)$ & $60 \%(15)$ & 0.551 \\
\hline & Survivors $n=25$ & $0 \%(0)$ & $28 \%(7)$ & $0 \%(0)$ & $72 \%(18)$ & \\
\hline \multirow[t]{2}{*}{ Lambda-cyhalothrin } & Dead $n=25$ & $4 \%(1)$ & $12 \%(3)$ & $0 \%(0)$ & $84 \%(21)$ & 0.289 \\
\hline & Survivors $n=25$ & $0 \%(0)$ & $28 \%(7)$ & $0 \%(0)$ & $72 \%(18)$ & \\
\hline \multirow[t]{2}{*}{ Permethrin $0,75 \%$} & Dead $n=25$ & $0 \%(0)$ & $20 \%(5)$ & $0 \%(0)$ & $80 \%(20)$ & 0.702 \\
\hline & Survivors $n=25$ & $0 \%(0)$ & $12 \%(3)$ & $0 \%(0)$ & $88 \%(22)$ & \\
\hline \multirow[t]{2}{*}{ DDT $4 \%$} & Dead $n=25$ & $12 \%(3)$ & $44 \%(11)$ & $0 \%(0)$ & $44 \%(11)$ & 0.385 \\
\hline & Survivors $n=25$ & $4 \%(1)$ & $32 \%(8)$ & $4 \%(1)$ & $60 \%(15)$ & \\
\hline Fenitrothion & Dead $n=50$ & $4 \%(2)$ & $42 \%(21)$ & $2 \%(1)$ & $52 \%(26)$ & - \\
\hline Bendiocarb 0,1\% & Dead $n=50$ & $6 \%(3)$ & $30 \%(15)$ & $0 \%(0)$ & $64 \%(32)$ & - \\
\hline Total & $\mathrm{n}=300$ & $3.7 \%(11)$ & $29.7 \%(89)$ & $0.7 \%(2)$ & $66.0 \%(198)$ & \\
\hline
\end{tabular}

Proportion and number of mosquitoes belonging to An. arabiensis specie and An. gambiae s.s. molecular form M, MS and S assessed after insecticide sensitivity in both dead and surviving (when available) mosquitoes.

doi:10.1371/journal.pone.0031943.t002

kdr-e mutation has never been detected in Senegal. On the other hand, kdr-w mutation has already been observed in 2005-2006 in Senegal at a rate of $9-12 \%$ in Dakar [36] and 19\% in Kedougou (Western Senegal) [37] that was lower than that observed in our study $(28 \%)$. In recent studies, the allelic $\mathrm{R}$ frequency was found to be higher in Ghana [17], similar in RDC [31] and lower in Guinea Conakry [15]. In this study, the presence of kdr-w mutation has been shown to precede the implementation of LLINs but their rate significantly increased after.

Resistance to pyrethroids and DDT in An. gambiae is known to associate closely with kdr-w $[11,14,27]$. In our study, the frequency of the kdr-w allele was significantly higher in resistant-selected samples confirming the association between $\mathrm{kdr}-\mathrm{w}$ mutation and the resistance phenotype to DDT and all pyrethroids tested. Moreover, a similar level of resistance was observed with DDT and all pyrethroids. Therefore a mutation of the sodium channel, that is the common target of both DDT and Pyrethroids, is likely to be involved in the observed resistance. However, $30 \%$ of specimens found among survivors presented the wild homozygote genotype. These findings support the hypothesis that target mutation is only one of the mechanisms implicated in insecticide resistance [11] and that metabolic resistance likely occurs in the An. gambiae population of Dielmo.

In our study, the presence of kdr-w mutation was mainly found in S molecular form of An. gambiae. It was absent in An. arabiensis and in the small sample of MS hybrids (4 specimens). Interestingly, kdr-w mutation was identified at a low rate $(9 \%)$ in the $M$ molecular form. Many studies reported the high frequency of kdrw mutation in molecular form $\mathrm{S}$ in Western and Central Africa and its low frequency or absence in molecular $\mathrm{S}$ form (see [37] for

Table 3. kdr-w mutation genotypes and allelic frequencies among dead and surviving mosquitoes after insecticide exposure.

\begin{tabular}{|c|c|c|c|c|c|c|c|c|}
\hline & & \multicolumn{3}{|l|}{ Genotype } & \multirow[t]{2}{*}{$\begin{array}{l}\text { Fisher exact } \\
\text { test } p\end{array}$} & \multicolumn{2}{|c|}{ Allelic frequency } & \multirow[t]{2}{*}{$\begin{array}{l}\text { Fisher exact } \\
\text { test } p\end{array}$} \\
\hline & & SS & SR & RR & & $\mathbf{S}$ & $\mathbf{R}$ & \\
\hline \multirow{2}{*}{$\begin{array}{l}\text { Deltamethrin } \\
0,05 \%\end{array}$} & Dead $n=25$ & $64 \%(16)$ & $36 \%(9)$ & $0 \%(0)$ & 0.002 & $82 \%(41)$ & $18 \%(9)$ & $<0.001$ \\
\hline & Survivors $n=25$ & $28 \%(7)$ & $40 \%(10)$ & $32 \%(8)$ & & $48 \%(24)$ & $52 \%(26)$ & \\
\hline \multirow[t]{2}{*}{$\begin{array}{l}\text { Lambda- } \\
\text { cyhalothrin }\end{array}$} & Dead $n=25$ & $60 \%(15)$ & $40 \%(10)$ & $0 \%(0)$ & 0.013 & $80 \%(40)$ & $20 \%(10)$ & 0.001 \\
\hline & Survivors $n=25$ & $24 \%(6)$ & $68 \%(17)$ & $8 \%(2)$ & & $58 \%(29)$ & $42 \%(21)$ & \\
\hline \multirow[t]{2}{*}{ Permethrin 0,75\% } & Dead $n=25$ & $52 \%(13)$ & $48 \%(12)$ & $0 \%(0)$ & 0.002 & $76 \%(38)$ & $24 \%(12)$ & $<0.001$ \\
\hline & Survivors $n=25$ & $20 \%(5)$ & $52 \%(13)$ & $28 \%(7)$ & & $46 \%(23)$ & $54 \%(27)$ & \\
\hline \multirow[t]{2}{*}{ DDT 4\% } & Dead $n=25$ & $76 \%(19)$ & $24 \%(6)$ & $0 \%(0)$ & 0.041 & $88 \%(44)$ & $12 \%(6)$ & $<0.001$ \\
\hline & Survivors $n=25$ & $48 \%(12)$ & $36 \%(9)$ & $16 \%(4)$ & & $66 \%(33)$ & $34 \%(17)$ & \\
\hline Fenitrothion & Dead $n=50$ & $50 \%(25)$ & $50 \%(25)$ & 0 & - & $75 \%(75)$ & $25 \%(25)$ & - \\
\hline Bendiocarb 0,1\% & Dead $n=50$ & $68 \%(34)$ & $30 \%(15)$ & $2 \%(1)$ & - & $82 \%(83)$ & $17 \%(17)$ & - \\
\hline Total & $\mathrm{n}=300$ & $50.7 \%(152)$ & $42 \%(126)$ & $7.3 \%(22)$ & - & $71.7 \%(430)$ & $28.3 \%(170)$ & - \\
\hline
\end{tabular}

Proportion and number of mosquitoes with kdr-w genotype SS (sensitive, sensitive), SR (resistant, sensitive) and RR (resistant, resistant) and corresponding allelic frequency assessed after insecticide sensibility in both dead and surviving (when available) mosquitoes.

doi:10.1371/journal.pone.0031943.t003 
Table 4. kdr-w genotypes and allelic frequencies among the different molecular forms of An. gambiae s.l.

\begin{tabular}{|c|c|c|c|c|c|}
\hline & & \multicolumn{4}{|c|}{ Molecular form of An. gambiae } \\
\hline & & An. arabiensis & $\mathbf{M}$ & MS & $\mathbf{S}$ \\
\hline \multirow{3}{*}{$\begin{array}{l}\text { Kdr-w } \\
\text { mutation }\end{array}$} & SS & $100 \%(11)$ & $82.0 \%(73)$ & $100 \%(2)$ & $33.3 \%(66)$ \\
\hline & SR & $0 \%(0)$ & $18.0 \%(16)$ & $0 \%(0)$ & $55.6 \%(110)$ \\
\hline & $\mathbf{R R}$ & $0 \%(0)$ & $0 \%(0)$ & $0 \%(0)$ & $11.1 \%(22)$ \\
\hline \multirow{2}{*}{$\begin{array}{l}\text { Allelic } \\
\text { frequency }\end{array}$} & $\mathbf{S}$ & $100 \%(22)$ & $91.0 \%(162)$ & $100 \%(4)$ & $61.1 \%(242)$ \\
\hline & $\mathbf{R}$ & $0 \%(0)$ & $9.0 \%(16)$ & $0 \%(0)$ & $38.9 \%(154)$ \\
\hline \multicolumn{6}{|c|}{$\begin{array}{l}\text { Proportion and number of mosquitoes belonging to An. arabiensis species and } \\
\text { An. gambiae S.S. molecular form M, MS and S and presenting kdr-w mutation } \\
\text { genotypes SS, SR, and RR (Fisher exact test } \mathrm{p}<0.001 \text { ) and corresponding allelic } \\
\text { frequency. } \\
\text { doi:10.1371/journal.pone. } 0031943 . \mathrm{t} 004\end{array}$} \\
\hline
\end{tabular}

review or recent studies [17,31]). The kdr-w mutation, in molecular form $\mathrm{S}$, has therefore spread or occurred west of the $5{ }^{\circ} \mathrm{W}$ limit identified by Santolamazza et al. [37]. It has been hypothesized that the difference in kdr-w mutation frequency in both molecular forms was related to a different origin of the mutation in the two populations or linked to different ecological or behavioral characters between $\mathrm{M}$ and $\mathrm{S}$ forms [37].

The use of pyrethroids as pesticides for agriculture and for net treatment have both been recognized as factors responsible for the selection of resistant mosquitoes in Sub-Saharan Africa [7-9]. Near Dielmo, although some gardening and rice culture are performed, the use of pesticide is limited. Therefore, agriculture probably had a limited role in the emergence of the resistance to insecticides in this area. In Kenya, a lower susceptibility of $A n$. gambiae to Permethrin was found in villages where Permethrin impregnated nets were implemented for one year as compared to villages without nets. The mechanism involved was postulated to include $\mathrm{kdr}$ mutation together with metabolic resistance [38]. In another study, an increased frequency of kdr was observed in villages with nets [39]. Insecticide treated nets were implemented in Dielmo in July 2008 as a part of the vector control study. We speculate that this may have contributed to the selection of pyrethroids resistant strains of An. gambiae.

In Dielmo, mosquitoes have been found to be totally susceptible to Bendiocarb, an insecticide belonging to the Carbamate class and to Fenitrothion (Organophosphate class) since we observed $100 \%$ mortality. Susceptibility of An. gambiae s.l. populations to Fenithrothion was also observed in all the sentinel sites in Senegal in 2008 [26] and 2010 [25]. On the other hand, a resistance to Bendiocarb appeared between 2008 and 2010 in 2/15 sentinel

\section{References}

1. Ceesay SJ, Casals-Pascual C, Erskine J, Anya SE, Duah NO, et al. (2008) Changes in malaria indices between 1999 and 2007 in The Gambia: a retrospective analysis. Lancet 372: 1545-1554.

2. O'Meara WP, Bejon P, Mwangi TW, Okiro EA, Peshu N, et al. (2008) Effect of a fall in malaria transmission on morbidity and mortality in Kilifi, Kenya. Lancet 372: 1555-1562.

3. Ministère de la Santé et de la Prévention (2010) Programme National de Lutte contre le Paludisme (2010). Rapport d'activités 2009. Dakar.

4. Trape JF, Sauvage C, Ndiaye O, Douillot L, Marra A, et al. (2012) New Malaria-Control Policies and Child Mortality in Senegal: Reaching Millennium Development Goal 4. J Infect Dis in press.

5. WHO (2008) World malaria report 2008. Geneva: World Health Oraganization. sites [25,26]. In other areas, An. gambiae s.l. presented a resistance [15-17] or an increased tolerance [31] to Carbamates and increased tolerance to Malathion, another member of the Oraganophosphate class [15,17]. In addition to pyrethroids, Carbamates (Bendiocarb and Propoxur) or Organophosphates (Fenitrothion, Malathion and Pirimiphos-methyl) are recommended by the WHO for IRS [40]. Until now, no IRS has been performed in Dielmo as part of the vector control strategy. Since complete susceptibility to Carbamates and Organophosphates has been detected in Dielmo, these insecticides should be used in priority if IRS were to be performed in this area. The reduced effectiveness of insecticides coincides with an important international effort to increase bed net coverage in African Countries in order to control malaria transmission. Notably, in Senegal 6 millions insecticide-treated nets were freely distributed to the populations between 2005 and 2010 [41,42]. Resistance to pyrethroids is worrying, since it is the only class of insecticide safe enough to be recommended for treatment of bed nets. It appears to have a significant impact on net or IRS efficacy [43]. In Dielmo, we have recently demonstrated a rebound and age shift in malaria cases two years after the implementation of nets [22]. Since resistance of mosquitoes to several insecticides is reported in various sentinel sites in Senegal, planning alternative strategies for vector control should begin. Indeed, in Senegal, the insecticide vector resistance management started in 2011 by shifting from Deltamethrin to Bendiocarb for IRS in six selected districts. This study underlines the need to carefully document resistance and its impact on the efficacy of interventions.

In conclusion, this study demonstrated an increased frequency of kdr mutation in An. gambiae after the implementation of LLINs in Dielmo (Senegal). This coincided with a cross-resistance to DDT and all pyrethroids observed in 2010. Resistance was associated with a higher kdr-w allele frequency in surviving specimens. Moreover, kdr-w mutation was detected in both $\mathrm{M}$ and $\mathrm{S}$ molecular forms of An. gambiae and significantly more frequently in molecular form S. On the other hand, mosquitoes were fully sensitive to Bendiocarb and Fenitrothion.

\section{Acknowledgments}

We thank Charles Bouganali and Babacar Ndiouck for their technical assistance, Dr S. Clarke for English correction and helpful comments, the villagers in Dielmo for their participation in the study for 20 years.

\section{Author Contributions}

Conceived and designed the experiments: MON. Performed the experiments: MON SS AG. Analyzed the data: CM. Contributed reagents/materials/analysis tools: LK. Wrote the paper: CM. Substantial improvement of the manuscript: OF JFT. Scientific supervision of the study: CS JFT.

6. WHO (2007) Insecticide-treatedmosquito nets: a WHO position statement Global malaria programme. Geneva: World Health Oraganization.

7. Diabate A, Baldet T, Chandre F, Akoobeto M, Guiguemde TR, et al. (2002) The role of agricultural use of insecticides in resistance to pyrethroids in Anopheles gambiae s.l. in Burkina Faso. Am J Trop Med Hyg 67: 617-622.

8. Vulule JM, Beach RF, Atieli FK, Roberts JM, Mount DL, et al. (1994) Reduced Susceptibility of Anopheles-Gambiae to Permethrin Associated with the Use of Permethrin-Impregnated Bednets and Curtains in Kenya. Med Vet Entomol 8: 71-75.

9. Czeher C, Labbo R, Arzika I, Duchemin JB (2008) Evidence of increasing LeuPhe knockdown resistance mutation in Anopheles gambiae from Niger following a nationwide long-lasting insecticide-treated nets implementation. Malar J 7: 189. 
10. Zaim M, Aitio A, Nakashima N (2000) Safety of pyrethroid-treated mosquito nets. Med Vet Entomol 14: 1-5.

11. Donnelly MJ, Corbel V, Weetman D, Wilding CS, Williamson MS, et al. (2009) Does kdr genotype predict insecticide-resistance phenotype in mosquitoes? Trends Parasitol 25: 213-219.

12. Fontenille D, Lochouarn L, Diagne N, Sokhna G, Lemasson JJ, et al. (1997) High annual and seasonal variations in malaria transmission by anophelines and vector species composition in Dielmo, a holoendemic area in Senegal. Am J Trop Med Hyg 56: 247-253.

13. Hargreaves K, Koekemoer LL, Brooke BD, Hunt RH, Mthembu J, et al. (2000) Anopheles funestus resistant to pyrethroid insecticides in South Africa. Med Vet Entomol 14: 181-189.

14. Chandre F, Darriet F, Manguin S, Brengues G, Carnevale P, et al. (1999) Pyrethroid cross resistance spectrum among populations of Anopheles gambiae s.s. from Cote d'Ivoire. Journal of the Am Mosq Control Assoc 15: 53-59.

15. Vezenegho SB, Brooke BD, Hunt RH, Coetzee M, Koekemoer LL (2009) Malaria vector composition and insecticide susceptibility status in Guinea Conakry, West Africa. Med Vet Entomol 23: 326-334.

16. Antonio-Nkondjio C, Fossog BT, Ndo C, Djantio BM, Togouet SZ, et al. (2011) Anopheles gambiae distribution and insecticide resistance in the cities of Douala and Yaounde (Cameroon): influence of urban agriculture and pollution. Malar J 10:154: 154 .

17. Hunt RH, Fuseini G, Knowles S, Stiles-Ocran J, Verster R, et al. (2011) Insecticide resistance in malaria vector mosquitoes at four localities in Ghana, West Africa. Parasit Vectors 4: 107.

18. Balkew M, Ibrahim M, Koekemoer LL, Brooke BD, Engers H, et al. (2010) Insecticide resistance in Anopheles arabiensis (Diptera: Culicidae) from villages in central, northern and south west Ethiopia and detection of kdr mutation. Parasit Vectors 3: 40

19. Betson M, Jawara M, Awolola TS (2009) Status of insecticide susceptibility in Anopheles gambiae s.l. from malaria surveillance sites in The Gambia. Malar J 8: 187.

20. Kelly-Hope L, Ranson H, Hemingway J (2008) Lessons from the past: managing insecticide resistance in malaria control and eradication programmes. Lancet Infect Dis 8: 387-389.

21. Trape JF, Rogier C, Konate L, Diagne N, Bouganali H, et al. (1994) The Dielmo Project - A Longitudinal-Study of Natural Malaria Infection and the Mechanisms of Protective Immunity in A Community Living in A Holoendemic Area of Senegal. Am J Trop Med Hyg 51: 123-137.

22. Trape JF, Tall A, Diagne N, Ndiath O, Ly AB, et al. (2011) Malaria morbidity and pyrethroid resistance after the introduction of insecticide-treated bednets and artemisinin-based combination therapies: a longitudinal study. Lancet Infect Dis 11: 925-32.

23. Gillies MT, Meillon B (1968) The Anophelinae of Africa South of the Sahara (Ethiopian zoogeographical region). Johannesburg: Publications of the South Africa Institute for Medical Research. 343 p.

24. WHO (1998) Test procedures for insecticide resistance monitoring in malaria vectors, bio-efficacy and persistence of insecticides on treated surfaces. Geneva: World Health Oraganization.

25. Diop A (2010) Rapports annuels du Projet OMS/GATES sur le contrôle et la biologie des vecteurs du paludisme. Programme National de Lutte contre le Paludisme, Ministère de la Santé et de la Prévention, Sénégal.
26. Diop A (2008) Rapports annuels du Projet OMS/GATES sur le contrôle et la biologie des vecteurs du paludisme. Programme National de Lutte contre le Paludisme, Ministère de la Santé et de la Prévention, Sénégal.

27. Martinez-Torres D, Chandre F, Williamson MS, Darriet F, Berge JB, et al. (1998) Molecular characterization of pyrethroid knockdown resistance (kdr) in the major malaria vector Anopheles gambiae s.s. Insect Mol Biol 7: 179-184.

28. Ranson H, Jensen B, Vulule JM, Wang X, Hemingway J, et al. (2000) Identification of a point mutation in the voltage-gated sodium channel gene of Kenyan Anopheles gambiae associated with resistance to DDT and pyrethroids. Insect Mol Biol 9: 491-497.

29. Fanello C, Santolamazza F, della TA (2002) Simultaneous identification of species and molecular forms of the Anopheles gambiae complex by PCR-RFLP. Med Vet Entomol 16: 461-464

30. Yadouleton AW, Padonou G, Asidi A, Moiroux N, Bio-Banganna S, et al. (2010) Insecticide resistance status in Anopheles gambiae in southern Benin. Malar J 9: 83 .

31. Koekemoer LL, Spillings BL, Christian RN, Lo TC, Kaiser ML, et al. (2011) Multiple Insecticide Resistance in Anopheles gambiae (Diptera: Culicidae) from Pointe Noire, Republic of the Congo. Vector Borne Zoonotic Dis 11: 1193-200.

32. Matowo J, Kulkarni MA, Mosha FW, Oxborough RM, Kitau JA, et al. (2010) Biochemical basis of permethrin resistance in Anopheles arabiensis from Lower Moshi, north-eastern Tanzania. Malar J 9: 193.

33. Ranson H, N'Guessan R, Lines J, Moiroux N, Nkuni Z, et al. (2011) Pyrethroid resistance in African anopheline mosquitoes: what are the implications for malaria control? Trends Parasitol 27: 91-98.

34. Abate A, Hadis M (2011) Susceptibility of Anopheles gambiae s.l. to DDT, malathion, permethrin and deltamethrin in Ethiopia. Trop Med Int Health 16: 486-491.

35. Djegbe I, Boussari O, Sidick A, Martin T, Ranson H, et al. (2011) Dynamics of insecticide resistance in malaria vectors in Benin: first evidence of the presence of L1014S kdr mutation in Anopheles gambiae from West Africa. Malar J 10: 261.

36. Pages F, Texier G, Pradines B, Gadiaga L, Machault V, et al. (2008) Malaria transmission in Dakar: A two-year survey. Malar J 7: 178 .

37. Santolamazza F, Calzetta M, EtangJ, Barrese E, Dia I, et al. (2008) Distribution of knock-down resistance mutations in Anopheles gambiae molecular forms in west and west-central Africa. Malar J 7: 74.

38. Vulule JM, Beach RF, Atieli FK, McAllister JC, Brogdon WG, et al. (1999) Elevated oxidase and esterase levels associated with permethrin tolerance in Anopheles gambiae from Kenyan villages using permethrin-impregnated nets. Med Vet Entomol 13: 239-244.

39. Stump AD, Atieli FK, Vulule JM, Besansky NJ (2004) Dynamics of the pyrethroid knockdown resistance allele in western Kenyan populations of Anopheles gambiae in response to insecticide-treated bed net trials. Am J Trop Med Hyg 70: 591-596.

40. WHO (2006) Pesticides and their application for the control of vectors and pests of public health importance. Geneva: World Health Organization.

41. Thwing JI, Perry RT, Townes DA, Diouf MB, Ndiaye S, et al. (2011) Success of Senegal's first nationwide distribution of long-lasting insecticide-treated nets to children under five - contribution toward universal coverage. Malar J 10: 86.

42. Roll Back Malaria. Focus on Senegal.progress and impact series. Geneva: World Health Organization.

43. N'Guessan R, Corbel V, Akogbeto M, Rowland M (2007) Reduced efficacy of insecticide-treated nets and indoor residual spraving for malaria control in pyrethroid resistance area, Benin. Emerg Infect Dis 13: 199-206.
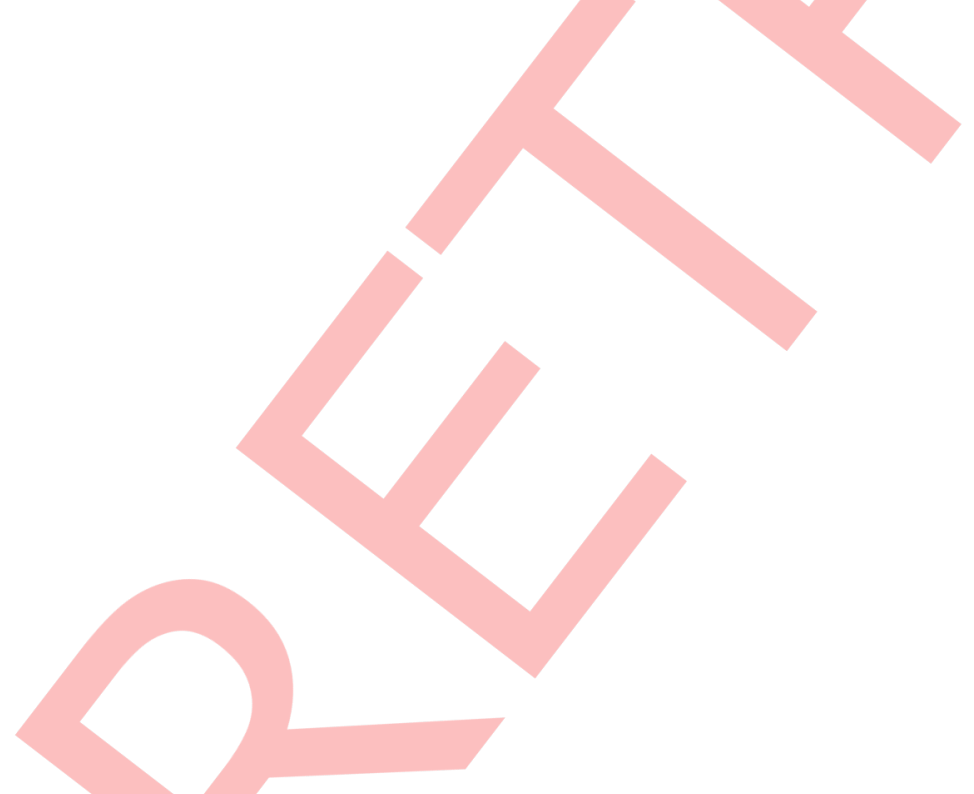